\title{
RELAÇÕES INDUSTRIAIS VERSUS SUPERVISÃO
}

LAERTE LEITE CORDEIRO *

Este artigo tem como objetivo fundamental o exame da problemática do relacionamento entre o Departamento de Relações Industriais e a Supervisão nas emprêsas. Seu conteúdo refere-se, especìficamente, às organizações industriais, porque êste é o setor onde mais fàcilmente se encontram dados de pesquisa e também porque êsse é o campo onde o desempenho de Relações Industriais é o mais atualizado e eficiente. A expressão Relações Industriais é usada neste artigo significando o mesmo que Administração de Pessoal, entendida esta no seu conceito mais amplo e atualizado. Por Supervisão entendem-se todos os níveis de comando na estrutura das organizações, incumbidos de algum planejamenకo, organização, direção e contrôle e colocados entre a Diretoria e o nível de simples execução. Cabe, ainda, lembrar — mesmo sem autorização de resultados de pesquisa acadêmica - que os problemas que serão tratados ao longo dêste artigo, assim como a maioria das recomendações que ao final se oferecem, podem ser estendidos às organizações comerciais, aos bancos, às emprêsas estatais e até mesmo, de certa maneira, à Administração Pública, eis que, a grosso modo, o panorama das relações e as circunstâncias mais amplas não diferem do que ocorre nas organizações de propósito industrial.

* Professor-Adjunto do Departamento de Administração Geral e Relações Industriais da Escola de Administração de Emprêsas de São Paulo, da Fundação Getúlio Vargas. 
O artigo principia por uma breve análise da realidade atual de Relações Industriais na Pequena, Média e Grande Emprêsa para estabelecimento do contexto dentro do qual ocorrem os problemas objeto de exame. Assentada a base, o artigo descreve as relações entre o DRI e a Supervisão nas emprêsas, com especial interêsse para as "imagens negativas reciprocas". Busca, a seguir, levantar os problemas que decorrem dos atritos e fricções que o relacionamento origina para, ao final, sugerir alguns novos caminhos que possam, eventualmente, levar à correção da problemática examinada.

Os comentários feitos em tôrno da realidade atual do desempenho funcional em Relações Industriais estão assentados em dados colhidos a partir de pesquisa descritiva realizada no Brasil. As considerações tecidas a respeito das relações entre o DRI e a Supervisão e, bem assim, as recomendações feitas no sentido da solução dos problemas são elaborações, com sabor especulativo, que têm seu lastro na docência universitária e na consultoria profissional, exercidas pelo autor há já alguns anos.

\section{O CAMPO DA LUTA}

A Pequena Emprêsa, situada ainda numa fase de dificuldades que são próprias de seu estágio de crescimento e de tamanho, desempenha a atividade de Relações Industriais de maneira primária e rudimentar ${ }^{1}$. $O$ sindicato não chega até ela, as imposições do direito do trabalho são aborrecidas, mas não chegam a ser complexas, não há recursos financeiros ou administrativos disponíveis para serem aplicados nessa área, os problemas com o pessoal podem ser resolvidos pelo próprio dono da emprêsa, ou por seu lugar-tenente, o guarda-livros. Não há, e nem poderia haver, um Departamento de Relações Industriais estruturado, especializado e eficiente, ao qual competisse administrar os recursos humanos. Por outro lado, a estrutura organizacional é

1 Bresser Pereira, L. C., Carvalho, A. R. 45 \& Leite Cordeiro, L., Administração Geral e de Pessoal na Pequena Emprêsa Brasileira, a ser publicado pela Fundação Getúlio Varg̣as, Rio de Janeiro, GB. 
"achatada", quase não se encontrando supervisores, e estando a administração geral e o comando direto nas mãos dos proprietários. Não há, portanto, maior lugar para tratamento do assunto que nos propusemos, no âmbito da Pequena Emprêsa.

Já a Média Emprêsa - cuja definição precisa constitui tarefa difícil - pressionada pelas contingências peculiares ao seu próprio processo de evolução, por um lado, e pelas dificuldades organizacionais, materiais e humanas típicas de seu tamanho, por outro, luta para chegar à condição de emprêsa grande, quando não o faz ùnicamente para permanecer com sucesso na posição em que se encontra.

Começa vagarosamente, e em função de suas necessidades operacionais, a melhorar seus padrões administrativos no que se refere aos recursos humanos que utiliza, ainda que Relações Industriais sejam a última área de desempenho funcional a merecer atenção, ao longo do processo de expansão. Já existe um setor para cuidar especificamente da problemática de seu pessoal, mas que não chega a ser o ambicionado Departamento de Relações Industriais, sendo apenas uma Seção de Pessoal que inicia a aplicação tecnológica ao mesmo tempo que realiza as obrigações legais referentes à manutenção de um Quadro de Pessoal. À medida que as operações se tornam mais complexas, que as atividades se ampliam e que se acelera a dinâmica organizacional, o dono já não pode administrar sem delegar a supervisores que terão de agir em seu lugar. Pressupõe-se a existência de alguns níveis hierárquicos e a organização, em sua estrutura, já assume a forma de uma pirâmide com maior número de níveis, atingindo altura maior .

Pode ser observado que a Emprêsa Média caminha para a especialização de funções, constitui-se em departamentos, organiza-se para enfrentar o embate do mercado e da conjuntura dos negócios. Tem início então o processo de equacionamento dos vários órgãos do qual deve fluir a consecução adequada de seus objetivos. Do funcionamento dinâmico da emprêsa decorre um relacionamento necessário entre a Seção de Pessoal e a Supervisão nos vários níveis. 
Em nosso entender, tal relacionamento ocorre de maneira relativamente tranquiila, por causa da timidez e da modéstia da Seção que só agora começa a adquirir importância organizacional, sem poder ainda oferecer uma grande contribuição, mas, ao mesmo tempo, sem fazer grandes exigências, especialmente de natureza burocrática, nem perturbar a tranqüilidade e a autoridade dos Supervisores. A Seção de Pessoal é um mal necessário que pode ser aceito enquanto não trouxer trabalho ou responsabilidades adicionais .

A Grande Emprêsa tem objetivos ambiciosos e amplos. As operações são em geral de grande porte, obrigando a um desempenho funcional eficiente e adequado que só pode ser conseguido a partir de uma divisão racional da totalidade do trabalho desempenhado pela emprêsa.

A especialização das funções é elevada a um alto grau de refinamento e a dinâmica das atividades obriga a delegação de autoridade de maneira generalizada. A estrutura organizacional assume a forma de uma pirâmide de base ampla com o vértice a uma grande distância. Os donos do capital e a administração de cúpula afastam-se do nível de execução, situando-se, entre a base e o tôpo, um conjunto de Supervisores que faz funcionar a máquina empresarial. O planejamento torna-se de relevância crescente e o contrôle passa a ser imprescindível. A burocracia aumenta sua importância em função da necessidade de tornar rotineiro o funcionamento da estrutura e de se impedir a ação de variáveis que possam comprometer a estabilidade da organização. A liberdade de decidir, que o dono da Pequena Emprêsa ostenta e que o supervisor da Emprêsa Média ainda detém, passa a ter um caráter limitado em todos os níveis da Grande Emprêsa. As limitações estão contidas no organograma, no manual de organização, no manual de procedimentos, nas descrições de cargos, nos regulamentos e nos formulários. Pode ainda ser encontrada nos departamentos de serviço e nas assessorias, a partir do exercício da autoridade funcional e das imposições burocráticas que afetam o desempenho do supervisor de 
linha. É nesse contexto que encontramos o Departamento de Relações Industriais da Grande Emprêsa brasileira ${ }^{2}$. A êle compete a busca, a escolha, o desenvolvimento, a remuneração, o registro e a manutenção dos recursos humanos de que necessita a emprêsa para alcançar eficientemente seus objetivos. O Departamento de Relações Industriais, na execução das tarefas mencionadas, substitui parcialmente os Supervisores, aparentemente servindo a cada um e a todos, a partir de uma contribuição especializada, que devia permitir desempenho mais adequado na linha e, por isso, ser acolhida calorosamente por todos os setores e níveis da emprêsa. Ao observador atento e experiente não escapará, todavia, o fato de que o relacionamento, teòricamente fácil e até tranqüilo, na realidade não ocorre assim, e, ao contrário, está repleto de atritos e de fricções que comprometem, com freqüência, não só o desempenho funcional do Departamento ou dos órgãos de linha mas, inclusive, das próprias emprêsas, dificultando a consecução de seus objetivos. De maneira geral, poderíamos afirmar que tais atritos e fricções decorrem das características e da problemática específica da Grande Emprêsa e que em nada diferem dos problemas de outros órgãos assessôres. Todavia, é nossa impressão que o relacionamento entre o Departamento de Relações Industriais e a Supervisão nos órgãos de linha têm certas peculiaridades que derivam de imagens negativas recíprocas, nem sempre assentadas em fatos e freqüentemente construídas emocionalmente, em razão das quais posições são assumididas, agressões cometidas, colaboração negada e prejuízos generalizados.

SE NÃo DIZEM, PENSAM...

Vejamos, em primeiro lugar, algumas das imagens que com certa freqüência se poderiam anotar, ouvindo-se Supervisores a comentarem sôbre o Departamento de Relações Industriais :

VAlle dA Silva, L. F. \& LeIte Cordeiro, L., A Função de Relações Industriais em Emprêsas Industriais do Grande São Paulo, pesquisa realizada em 1965 e não publicada. 
"O Ladrão de Prestígio" - "Tudo o que acontece de bom e de positivo para nossos subalternos é sempre divulgado como sendo obra do Departamento de Relações Industriais. Os aumentos de salários, as promoções, os benefícios são aparentemente conseguidos pelo Departamento de Relações Industriais. Agora, quando decisões que não satisfazem os empregados e que não os deixam contentes têm de ser tomadas, são sempre divulgadas como sendo iniciativa e execução dos Supervisores. As dispensas, suspensões, a disciplina, o fazer trabalhar, ficam por nossa conta. A verdade é que o Departamento de Relações Industriais vem querendo provar a todos os empregados e à administração de tôpo que realmente merece maior importância e status do que normalmente possui, e isto tudo às nossas custas".

"O Castelo da Burocracia" -- "O Departamento de Relações Industriais só serve para dar trabalho aos outros. Nós, os supervisores, nos órgãos de linha, vivemos sob tensão permanente com um milhão de coisas por fazer e sem tempo para executá-las. Então aparece o Departamento de Relações Industriais e inventa formulários, documentos, entrevistas, manuais e uma interminável papelada, só Deus sabendo para que. Por outro lado, na maioria das vêzes, nós nem sequer sabemos exatamente o que está acontecendo, para que serve êsse ou aquêle formulário e o que vai acontecer com o documento depois de preenchido. $O$ Departamento de Relações Industriais encastela-se na sua amada burocracia e distribui trabalho para todos. Quase todo o tempo, fazemos o que êles pedem, só porque somos obrigados".

"O Bom Samaritano" - "Às vêzes, nós da Supervisão, chegamos à conclusão de que o Departamento de Relações Industriais é o "bom samaritano" dentre os órgãos da emprêsa e que existe apenas para, através de seu responsável, "especialista em Relações Humanas", proteger os "pobrezinhos" dos empregados contra as agressões dos "abomináveis homens de supervisão", especialmente no Setor de Produção. É algo assim como o advogado dos "fracos 
e oprimidos" ou um "pastor de almas". Mas nós não somos animais, somos humanos como todos os demais. Estamos na década dos sessenta em grandes emprêsas e não no tempo da Revolução Industrial. O problema é que o Departamento de Relações Industriais e os Supervisores têm objetivos diversos dentro da emprêsa. A nós compete produzir com eficiência e alta produtividade e ao Departamento de Relaçôes Industriais cabe fazer o bem. Nem sempre as duas coisas podem ocorrer simultâneamente".

"O Departamento de Polícia" - "Quando não é "bonzinho", o Departamento é, de maneira geral, visto como indo ao outro extremo. Vive procurando defender a organização do ataque dos bandidos dos empregados que a querem dilapidar. Para realizar essa função e manter-se coerente com sua filosofia, o Departamento de Relações Industriais "espia", investiga e pune, criando para a relação chefe-subalterno um clima negativo e de difícil eliminação. Os empregados estão sempre a se defenderem de nós, porque representamos a emprêsa, o que dificulta sobremaneira nosso trabalho. Em tudo que acontece, sente-se a sombra do Departamento de Relações Industriais pairando sôbre nossas cabeças. No final das contas, quem paga é sempre o Supervisor".

"O Mal Necessário" - "Não fôssem as imposições legais e os sindicatos, quando ativos, deveríamos acabar com êsses burocratas do Departamento de Relações Industriais. A emprêsa gasta tanto dinheiro com essa função que, ao contrário de auxiliar, inventa trabalho e não fala a nossa língua. Seria muito melhor voltarmos à pequena Seção de Pessoal, que fazia o essencial, e utilizarmos o resto do dinheiro, atualmente alocado ao Departamento de Relações Industriais, nos setores produtivos da emprêsa. Aí, quem sabe, poderíamos ter o equipamento, o laboratório ou o espaço que há tanto tempo pedimos à Direção sem conseguir".

"Centro de Politiqueiros e Manipuladores de Pessoas" "O Departamento de Relações Industriais, em geral, só 
serve para complicar as coisas. Ali, têm início as "ondas", é onde se origina o grapevine. Como não tem muito que fazer, fica a inventar coisas . E nós, do lado de fora, escutamos muitas conversas sôbre Relações Humanas, Assistência Social, como resolver problemas dos empregados e assim por diante. Nem sempre parece-nos muito ético o desempenho dêsse Departamento que interfere em demasia na intimidade das pessoas. Seria muito melhor se desse mais atenção ao atendimento daquilo que os Supervisores necessitam em têrmos de recursos humanos. Vamos todos falar menos sôbre felicidade e bem-estar e um pouco mais em eficiência e produção, é o que nosso subdesenvolvido país tem necessidade".

Ocorre, todavia, que o Departamento de Relações Industriais, por seus representantes, também tem sua maneira peculiar de ver a Supervisão e os Supervisores. Entre outras, que podemos registrar em nossa experiência profissional, encontraríamos as seguintes imagens:

“Exploradores dos Empregados" - "São em geral homens que se preocupam apenas com a produção, materialistas, frios, desprovidos de compreensão humana. Sentem-se como se fôssem donos das pessoas de seus subalternos, sem o menor cuidado para com a emoções e os sentimentos dos mesmos. Só desejam extrair o máximo dos empregados em têrmos de produção, como se os homens fôssem máquinas. Entendem apenas a linguagem dos números, das tabelas e das fórmulas e gráficos. Na hora de fazer concessões aos empregados, somos nós do Departamento de Relações Industriais que temos de lutar para conseguir o endôsso da Direção. Os Supervisores estão muito ocupados para pensar nessas coisas sem importância.

"Desorganizados" — “Quase sempre, a supervisão é exercida por homens que não conseguem entender no que consiste uma grande organização. Acham que a burocracia é necessàriamente sinônimo de papelada inútil e que serve apenas para criar confusão. Não colaboram, mas exigem de nós, do Departamento de Relações Industriais, mais do 
que podemos dar. Nunca têm tempo para fazer o que pedimos e, quando "magnânimamente" concedem, quase nunca fazem um bom trabalho. Limitam-se a assinar as conclusões das análises de cargos dos seus subordinados, sem ao menos lê-las. Preenchem os formulários de avaliação de desempenho de seus subordinados, dando notas elevadas para todos, indistintamente, ou, simplesmente, não realizam o trabalho de integração dos novos empregados admitidos da maneira pela qual estabelecemos. Contrôle constitui para êles quase uma obscenidade e sentem-se ofendidos quando simplesmente é mencionado. Por outro lado, deleitam-se em utilizar seu poder decisório no que se refere ao pessoal, pois é exatamente quando se auto-afirmam realmente como chefes. Têm especial predileção em despedir um empregado de seu setor para que possam sentir-se importantes e depois mandar o homem ao Departamento de Relações Industriais para as providências necessárias. E somos nós que temos de "roer os ossos", resolvendo todos os problemas, particularmente junto à Diretoria, quando o empregado dispensado obriga a que se efetuem pagamentos de elevadas indenizações devidas à sua antigüidade na emprêsa".

"Incompetentes" - "Cada um dos supervisores se considera o líder máximo existente na indústria brasileira. A verdade é que, nos níveis mais baixos, falta a formação devida e, em geral, os chefes originam-se dos escalões hierárquicos inferiores. Hoje ostentam as divisas em seus braços, mas retêm a mentalidade de empregado. Nos níveis mais elevados, é encontradiço o supervisor com instrução universitária, que não foi, entretanto, devidamente preparado para a tarefa de supervisionar pessoas, mas para o desempenho de tarefas técnicas específicas. Veja-se o caso dos engenheiros e dos economistas. Assim, a não ser excepcionalmente, a competência dos supervisores é pequena, criando-se um problema para o Departamento de Relações Industriais e para o funcionamento da organização como um todo". 
"Senhores Feudais" - E como se comportam normalmente os supervisores. Egoístas, preocupados exclusivamente com seus pequenos feudos, deixam de ver a emprêsa como um todo e a administração como um processo integrado. Preocupam-se em demasia com suas respectivas reputações profissionais e com o status de suas unidades e, por vêzes, sacrificam os interêsses da emprêsa. É difícil estabelecer diálogo com êsses homens que procuram permanentemente defender "suas coisas". Não aceitam autoridade funcional e sabem tudo a respeito de tudo, melhor, inclusive, do que qualquer especialista. Não aceitam $o$ treinamento, não lhes agrada que se fale em pesquisa, não se esforçam para se atualizarem em função de um desempenho melhor. Constroem muralhas ao seu redor que nem sempre o Departamento de Relações Industriais consegue transpor.

TODO MUNDO SOFRE

À medida que se podem aceitar como verdadeiras e representativas as imagens que tentamos reproduzir em nossa análise do relacionamento entre o Departamento de Relações Industriais e a Supervisão, deve-se, ao mesmo tempo, concluir que dos atritos e friç一ões intrínsecas decorre uma série de problemas que afetam a Grande Emprêsa brasileira .

Para a emprêsa, tal problemática dificulta a consecução dos objetivos almejados, frustra a implementação das grandes diretrizes da organização, tornando acidentado o seu caminhar. Desenvolve um clima de agressão e de defesa mais do que de cooperação e contribuição entre órgãos e indivíduos. Cria, por vêzes, uma imagem pública negativa, porque as paredes não detêm os efeitos do conflito interno nas relações da emprêsa com a comunidade. Impede freqüentemente o desenvolvimento pessoal dos indivíduos, os quais, ao mesmo tempo, constituem-se em sujeito e objeto da problemática, limitando sua participação e contribuição. Há, enfim, um conjunto de conseqüências negativas que, em linhas gerais, comprometem os resultados e os sucessos da organização. 
Para a Supervisão, as friç̧ões e os conflitos, nas relações com o Departamento de Relações Industriais, trazem como consequiência, entre outras, o fato de deixarem de poder usufruir dos bons serviços de um Departamento que, peio menos teòricamente, existe para servi-la. Não se quer dizer que, pelo fato de as relações não serem boas, o Departamento deixará de existir ou que as Gerências e Chefias deixarão de ter que se servir do que venha a ser produzido pelos homens de pessoal. Mas é necessário entender que o clima que permeia as relações impedirá o resultado melhor e mais efetivo, dificultando o desempenho, mais do que gerando benefícios. Além disso, as tarefas que competem aos Supervisores serão eventualmente executadas de maneira menos eficiente na medida em que haja desentendimento entre as partes, não sendo difícil se estabelecerem, em têrmos práticos, os problemas que podem advir de tal situação. Parece-nos, todavia, ainda mais grave o fato de que do desacôrdo de imagens e da problemática do relacionamento podem ocorrer vítimas entre os próprios empregados, seja individual, seja conjuntamente, pelo sacrifício do estímulo, da motivação, do empenho e da dedicação, luxo que nenhum chefe, departamento ou emprêsa se pode permitir.

Para o Departamento de Relações Industriais e para os profissionais que abriga, a situação de conflito organizacional, que descrevemos, cria uma série de obstáculos. À medida que é mal visto, ou que não é aceito por aquêles a quem deve servir, surge necessàriamente uma tendência para o esvaziamento de seu desempenho em têrmos de conteúdo da contribuição ofertada à organização como um todo. Torna-se cada dia mais difícil comprovar a validez de sua existência e a qualidade de seus serviços. $O$ status do órgão começa a cair, o crescimento profissional de suas responsabilidades começa a atrofiar-se, diminui o estímulo, os cargos em Relações Industriais deixam de ser atrativos e os salários passam a ser comparativamente mais baixos que nos demais setores da atividade empresarial. A consequiência de todos êsses fatôres é que o Departamento de Relações Industriais não pode subsidiar, como deveria, o 
trabalho dos Supervisores, deixando, dessa forma, de contribuir de maneira melhor e mais eficaz para a consecução dos objetivos empresariais. Frustra os responsáveis pelas atividades de Relações Industriais pela condição pouco elevada de que desfrutam, quando comparados com outros setores da emprêsa. Finalmente, e de maneira cumulativa, provoca o isolamento do Departamento na organização, bem como dificulta, de maneira crescente, o diálogo necessário para o sucesso da relação e da consecução dos objetivos de ambas as partes. Está claro, por outro lado, que nem sempre os profissionais de Relações Industriais aceitam passivamente tal situação. Pode-se, inclusive, observar, a luta do Departamento de Relação Industrial para adquirir status, que não lhe é dado gratuitamente, à custa de abarcar um número crescente de atividades diversas, que nem sempre estão vinculadas diretamente aos recursos humanos, seu objeto específico. Além das atividades já consagradas como "Proteção à Fábrica", cuja vinculação às Relações Industriais poder-se-ia discutir num plano teórico há outras, como contrôle da frota de veículos, comunicações, zeladoria, conservação de edifícios, etc., que já começam a ser reivindicadas pelo Departamento em questão. Isto para não falar dos que advogam Relações Públicas como preocupação típica e pertinente a ser vinculada aos Departamentos de Relações Industriais. De qualquer forma, ainda assim o resultado dêsses esforços não é positivo, pois são criadas outras zonas de conflito a partir da disputa sôbre as esferas de competência entre os vários órgãos componentes da mesma estrutura.

Em resumo, o que se vê é que há problemas sérios que decorrem do relacionamento inadequado entre as duas entidades, Relações Industriais e Supervisão, a afetarem sèriamente a emprêsa na consecução de seus objetivos. As duas categorias referidas também padecem pela insuficiência de suas respectivas contribuições funcionais. $\mathrm{Na}$ verdade, todo mundo sofre ... 


\section{ABRINDO NOVOS CAMINHOS}

Muito do que se possa dizer a respeito do comportamento típico e das atitudes correntes da Supervisão para com o Departamento de Relações Industriais terá, talvez, dupla e fundamental justificativa. Poder-se-ia quiçá, neste final, usar algumas linhas para aplicar a muitos Supervisores um generoso "puxão de orelhas", recomendando-lhes compreensão, conformismo, sensibilidade, "relações humanas". Parece, todavia, que mais do que buscar culpados pela situação ou tecer críticas contundentes, vale a pena dirigir aos profissionais de Relações Industriais, responsáveis pela adequada administração dos recursos humanos das emprêsas, algumas recomendações específicas, visando a abrir novos caminhos para minorar ou solucionar a problemática examinada neste artigo.

Definição dos Objetivos e do Papel de Relações Industriais - Chegou a hora de os homens de Relações Industriais pensarem em definir mais claramente, para o mundo empresarial, os reais objetivos dessa área funcional da emprêsa.

- As imagens que a Supervisão tem de Relações Industriais são realmente injustas porque totalmente inverídicas?

- Será que o papel de Relações Industriais já está suficientemente claro e é tão indiscutível para todos os profissionais dêsse campo, em tôdas as emprêsas e em todos os países?

- Será que não existe preocupação excessiva com a felicidade dos empregados, proteção paternalista inadequada, manipulação de pessoas ou desempenho policial na atividade de Relações Industriais, na maioria das grandes emprêsas?

- Será que, em função da necessidade de ganhar maior status profissional e organizacional, o Departamento de Relações Industriais não se está encastelando por de- 
trás de formulários e de uma burocracia exagerada, confundindo os Supervisores mais do que contribuindo para seu melhor desempenho?

Tôdas essas perguntas estão a exigir cuidadosa e ampla discussão para que se possa esperar efetivamente a eliminação dos atritos e fricções existentes entre o Departamento de Relações Industriais e os demais órgãos da emprêsa. Parece-nos cabível a recomendação aos profissionais de Relações Industriais para que se empenhem, ao máximo, no sentido de determinar os seus objetivos de maneira clara e estabelecer um papel organizacional preciso para o campo de atividade que lideram. Não é mais possível que o Departamento de Relações Industriais seja visto como mal necessário ou atividade não produtiva. Os conceitos de "Bom Samaritano" ou de "Departamento de Polícia". precisam ser extintos. É importante que Relações Industriais sejam vistas como uma área funcional da emprêsa, que tem uma tarefa administrativa superior. e que seus responsáveis compreendam que seu status só crescerá à medida que seu papel seja executado com eficiência e produtividade, de olhos voltados para a economia da emprêsa e para a consecução de seus objetivos. Está claro que o respeito e a valorização da dignidade humana devem ser constantes em Relações Industriais, mas não cometamos o exagêro de imaginar que só êsse Departamento é responsável por tais valôres. O gerente de Relações Industriais tem de ser tão "especialista" em Relações Humanas como os chefes de linha, de tal forma que seu Departamento venha a treinar todos para a aquisição dessas habilidades Enquanto tudo isso não acontecer, sofrerão as emprêsas, os chefes, os empregados e, conseqüentemente, a economia dos respectivos países.

Relações Públicas de Relações Industriais - $\mathrm{O}$ dito popular "não basta que sejamos honestos; é preciso que todos o saibam" é um pouco cínico, mas é muito prático, à guisa de conselho, aos homens de Relações Industriais. Na verdade, não adiantará muito que os que lutam nesse campo 
estejam convictos da validade, da importância e da contribuição do Departamento de Relações Industriais nas emprêsas. É importante que se demonstre o fato aos Supervisores dos órgãos de linha, quando não à própria Diretoria. Não nos referimos, está claro, ao esfôrço de relações públicas desprovido de conteúdo e até amoral.

O que recomendamos é uma campanha de esclarecimento da opinião interna das emprêsas sôbre qual é ou qual pode ser a contribuição do Departamento de Relações Industriais aos demais órgãos. Compete aos responsáveis por Relações Industriais uma ação missionária de catequese que possa modificar a imagem, em geral negativa, do Departamento. Êsse trabalho, evidentemente, só poderá ser realizado à proporção que Relações Industriais tenham seus objetivos e seu papel conscientemente definidos que sejam desenvolvidos através de fatos que possam comprovar o conteúdo da ação missionária. Enquanto homens de Relaçס̄es Industriais não tiverem sensibilidade para se aperceberem de que a imagem negativa que desfrutam junto aos Supervisores de linha produz uma necessária reação, não haverá solução para o problema.

É mister entender que as imagens negativas a respeito do Departamento de Relações Industriais existem em função, talvez, do próprio descuido dos responsáveis pelo Departamento ou devido ao próprio curso da industrialização ocorrido no mundo moderno. $\mathrm{O}$ que se recomenda, portanto, aos administradores de recursos humanos das emprêsas, é compreensão para o problema e suas causas, bem como uma ação prática e objetiva no sentido de mudança da imagem Departamento de Relações Industriais.

Desenvolvimento do Campo Profissional - A maneira mais fácil de dar sustentação a qualquer tentativa para melhoria da imagem do Departamento de Relações Industriais e da respectiva atividade profissional nas emprêsas será, ainda e sempre, a constituição de um lastro de knowhow específico, cuja necessidade seja estabelecida de maneira irreversível por aquêles cujas tarefas recebem o seu 
subsídio. Propõe-se, portanto, o máximo empenho por parte dos homens de Relações Industriais para o desenvolvimento dêsse campo profissional, visando ao aperfeiçoamento contínuo de sua contribuição efetiva às organizações. O modus faciendi não é sofisticado e nem constitui novidade: o amparo decidido à pesquisa, tanto no que se refere ao desenvolvimento e aperfeiçoamento da tecnologia de recursos humanos na emprêsa, quanto no que diz respeito às ciências que lhe dão sustentação e coerência, como a Psicologia, Sociologia, Direito, Administração e Economia, entre outras. É necessário fazer com que as Relações Industriais sejam, mais do que simplesmente um campo de aplicação estreita e rudimentar, uma oportunidade de demonstração de habilidades e conhecimentos jurídicotrabalhistas, ou um papel político no drama ou comédia das relações com os sindicatos. É necessário auxiliar a Universidade a auxiliar os profissionais, para que seja possível caminhar adiante do tempo, inovando e procurando oportunidades de disputar um lugar cada ve $z$ mais alto entre as áreas profissionais de maior destaque dentro das emprêsas. Recomenda-se abrir as portas aos pesquisadores interessados, incluir nos orçamentos verbas para pesquisas em Relações Industriais e áreas correlatas, receber nas emprêsas estudantes universitários na qualidade de estagiários, e relatar experiências práticas nas revistas técnicas especializadas a fim de ampliar o conhecimento de Relações Industriais. Quando tudo isto tiver sido feito, talvez seja possível:

- definir melhor os objetivos e o papel de cada Departamento de Relações Industriais, em cada emprêsa;

- modificar a imagem negativa, atualmente vigente;

- contribuir mais eficientemente para a organização;

- melhorar o status da função e do profissional;

- tornar menos conflitante o relacionamento com a Supervisão. 
Formação do Profissional de Relações Industriais - A carga que se pretende colocar nos ombros dos profissionais de Relações Industriais é um fardo pesado. Se lhes pede uma definição perante o mundo empresarial, uma ação missionária de catequese e uma atitude aberta, e de elevado sentido para com a Pesquisa. E para que a tarefa possa ser executada, deve-se-lhes pedir mais, insistindo que somente o profissional competente, bem formado e atualizado - conceitual e tècnicamente — terá condições para tanto. Do improvisador ou do amador não se pode exigir uma realização dessa natureza. Para êsses não há mais lugar. $\mathrm{O}$ que se recomenda, então, àqueles que desejam se encaminhar para essa área de desempenho funcional e aos profissionais já em exercício, é que procurem, da melhor maneira ao seu alcance, encontrar condições de formação adequada ou de aperfeiçoamento profissional permanente, a fim de se colocarem à altura das solicitações que o momento histórico das Relações Industriais impõe. Parece de extrema importância o movimento associativo dos profissionais de Relações Industriais, que se pode observar em quase todos os países das três Américas, porque significa intercâmbio de experiências, aquisição de novos conhecimentos, melhoria da condição individual de contribuição. A realização de Congressos de Relações Industriais, nacionais ou internacionais, servindo ao propósito fundamental de divulgar teorias, metodologia e práticas que inovam o campo e melhoram o desempenho dos participantes em suas emprêsas é, sem dúvida, iniciativa que deve ser estimulada. $O$ incremento dessas atividades, com a participação cada vez maior de profissionais de Relações Industriais, é que assegurará, fundamentalmente, a possibiliadde de sucesso das recomendações anteriores. Enquanto o homem de Relações Industriais não tiver condições para um diálogo, em pé de igualdade, com o seu colega de produção, vendas ou finanças, a imagem do Departamento que lidera continuará sendo fraca e negativa. Mesmo porque, talvez, o seu desempenho não seja realmente dos mais adequados ou eficientes, justificando, assim, o mau conceito. 
A realidade atual da atividade de Relações Industriais, examinada à luz de uma classificação das emprêsas industriais em pequenas, médias e grandes, demonstra a inexistência de qualquer raçionalização na administração dos recursos humanos, no primeiro caso, um desempenho racional incipiente, no segundo, e um desempenho altamente burocratizado e sofisticado, no terceiro.

Com relação à problemática do relacionamento entre o Departamento de Relações Industriais e a Supervisão pode-se dizer que não cabe discussão no que se refere à Pequena Emprêsa, pois que nela não se encontra tal departamento e quase não há supervisores. Já na Emprêsa Média o Departamento existe, porém de maneira tímida e modesta, sem fazer grandes exigências e por isso o relacionamento é relativamente tranqüilo e sem maiores conflitos. Todavia, na Grande Emprêsa, o relacionamento entre o Departamento de Relações Industriais e a Supervisão, que devia ser fácil e sem problemas, é, muito ao contrário, cheio de atritos e fricções que decorrem de peculiaridades da relação e que geram imagens negativas recíprocas. Tal situação leva a uma série de problemas para a Organização, para o próprio Departamento de Relações Industriais e para a Supervisão. Soluções-tentativas para essa problemática estão contidas nalgumas recomendações aos homens de Relações Industriais, entre as quais a definição clara e precisa dos objetivos e. do papel do Departamento de Relações Industriais na emprêsa, a necessidade de "fazer relações públicas" de Relações Industriais, a importância do desenvolvimento do campo profissional e, finalmente, a formação dos profissionais de Relações Industriais. 